\title{
Microinjection moulded polyetheretherketone biomaterials as spinal implants: physico-chemical and mechanical characterisation
}

\author{
C. L. Tuinea-Bobe ${ }^{\text {a }}$, H. Xia ${ }^{b}$, Y. Ryabenkova ${ }^{a}$, J. Sweeney ${ }^{a}$, P.D. Coates ${ }^{a}$, G. Fei ${ }^{b}$ \\ ${ }^{a}$ School of Engineering, University of Bradford, UK \\ ${ }^{\mathrm{b}}$ Polymer Research Institute, Sichuan University, China \\ *corresponding author Email: c.tuinea-bobe@bradford.ac.uk
}

\begin{abstract}
Polyetheretherketone (or PEEK) is a thermoplastic polymer known for its high plasticity and toughness and has been widely employed as a material for a variety of load-bearing medical devices ranging from trauma implants to interspinal spacers and femoral stems. While being inherently chemically inert and therefore biocompatible and having very short lived post-radiation free radicals, PEEK presents different mechanical properties depending on its degree of crystallinity. It can be processed via extrusion, injection or compression moulding. However, these techniques do not allow high precision control over the fine morphological structure that strongly influences mechanical properties. Microinjection moulding, in contrast, makes it possible to produce fine details of medical implants with high precision and accuracy. Another advantage of this method is the controlled production of the material with heterogeneous structure due to variations in crystallinity. Having stiffness in the middle of the sample different from that at the edges enables a structure that mimics the bone/cartilage parts of an implant. This paper reports on the manufacturing of PEEK components by microinjection moulding, and their characterisation by physico-chemical (XRD, SAXS, TEM, FTIR, POM) and mechanical (tensile testing) means, in order to assess the suitability of use for biomedical application, such as spinal implants. We discuss the influence of such parameters as mould temperatures, injection speeds and hold pressures on the crystallinity and mechanical properties of the material.
\end{abstract}

\section{Introduction}

Polyetheretherketone (or PEEK) is a linear thermoplastic polymer with aromatic ring monomers connected via ketone and ether functional groups. PEEK's chemical structure, with little or no branching as well as sterical rigidity, is responsible for its exceptional mechanical, thermal and radiation resistance. It is thus a desirable candidate as a biomaterial in trauma and orthopaedics, as well as for spinal applications. Indeed, it has been employed as a spinal implant since the 1980s [1] and by the late 1990s PEEK has been considered as a lightweight and high performance material to substitute for metal implant components $[2,3]$. The aromaticity of the constituent monomer blocks results in a remarkable gamma radiation and electron beam resistance as well as exceptional biocompatibility [4]. However its mechanical and physico-chemical properties strongly depend on the processing history and, in turn, morphology [5]. PEEK can be processed using a variety of commercially available techniques including extrusion, injection and compression moulding, at temperatures between 390 and $420^{\circ} \mathrm{C}[1,6]$. These methods allow the production of materials with different degrees of crystallinity, though normally no higher than $40 \%$ due to slow crystallisation kinetics above $30 \%[7,8]$. There is evidence that the intrinsic mechanical properties of PEEK, such as stiffness, fracture toughness, creep resistance and low susceptibility to fatigue, are positively correlated with its crystallinity [9]. It has also been reported that it is possible to produce injection moulded PEEK with heterogeneous crystallinity [10]. Microinjection moulding is an ultra-high 
precision technique used to produce high value polymer devices for a range of markets including medical devices (orthopaedics, drug delivery systems, surgical tools, diagnostic devices), optics (diffractive, refractive, freeform) and automotive (sensor components, sealing components, injectors) [11]. This manufacturing technique allows for the production of samples with high precision and also provides the potential for crystallinity that varies within a single sample. This feature can be of a great importance when producing materials for bone augmentation, where the implant needs to mimic both cortical and cancellous bone that differ significantly from each another in their mechanical properties [12]. There are available studies of the crystallinity of PEEK via DSC [13] and SAXS [14]. However, to the best of our knowledge there is no systematic investigation of PEEK microinjected moulded materials that attempts to relate spatially varying crystallinity to mechanical properties. We have employed a variety of techniques including XRD, FTIR, SAXS, polarised optical microscopy and TEM to study the crystallinity of the microinjection moulded materials. These data are related to the mechanical performance as observed by tensile testing.

\section{Materials and methods}

\section{Sample preparation}

Materials for this study were prepared using a sprue-less Battenfeld Microsystem 50 micro-injection moulding machine with a nozzle diameter of $5 \mathrm{~mm}$. Schematic drawings of the part and the specimen's areas of interest are given in Fig 1.a and 1.b respectively. The material used was the Victrex PEEK 450G. The melt temperatures were set for the various areas of the machine at 420 (nozzle), 400 (barrel) and $390^{\circ} \mathrm{C}$ (plasticizing area). The injection moulding parameters used were dictated by the material processability and are presented in Table 1 (columns 1, 2 and 3). The material is plasticized by a rotating screw positioned at a $45^{\circ}$ angle and subsequently pushed into a very accurate metering chamber. Then, the injection of the material into the cavity is performed by the injection piston through the barrel $\left(400^{\circ} \mathrm{C}\right)$ and the sprue-less nozzle $(420 \mathrm{C})$ into the cavity. The PEEK pellets were dried in a Motan drier at $120 \mathrm{C}$ for $5 \mathrm{~h}$ before preparation.

\section{Materials characterisation}

TEM was performed using a FEI Tecnai $\mathrm{G}^{2}$ F20 S-TWIN transmission electron microscope, operating at an accelerating voltage of $200 \mathrm{kV}$. The PEEK samples were cryo-microtomed under a liquid nitrogen cushion using a Leica EM UC6 microtome to obtain ultrathin cryo-sections of $70-80 \mathrm{~nm}$ thickness, which were collected and directly supported on a copper grid for observation.

Polarised Optical Microscopy was performed using Keyence VHX $1000 \mathrm{C}$ microscope equipped with 500 to 5000 magnification lenses.

XRD diffraction patters were acquired using a Bruker D8 Discover diffractometer operating at $40 \mathrm{kV}$ and $25 \mathrm{~mA}$ with $\mathrm{Cu} \mathrm{K}_{\square}$ radiation $(\lambda=1.5406 \AA$ ) , additionally equipped with a two-dimensional VÅNTEC500 detector for 2D image and pattern processing and manipulation. Data analysis/crystallinity evaluation have been performed using OriginPro software.

FTIR spectra were acquired using Nicolet iS50 Thermo Scientific FTIR spectrometer equipped with a built-in single reflection diamond ATR module. The spectra were recorded in the absorbance mode from 4000 to $375 \mathrm{~cm}^{-1}$ at $2 \mathrm{~cm}^{-1}$ resolution averaging 32 scans. The spectral data were processed using OriginPro and Casa XPS software for peak fitting and crystallinity evaluations.

The SAXS investigation was carried out at BL16B1 beam-line at Shanghai Synchrotron Radiation Facility (SSRF), China. The focus spot size was $0.3 \times 0.2 \mathrm{~mm}^{2}$. A radiation wavelength of $1.24 \AA$ was 
applied. Two different sample-to-detector distances, $2074.7 \mathrm{~mm}$ and $5088.6 \mathrm{~mm}$, were employed to explore lamellae reflection and central diffuse scattering signals, respectively. The exposure time was $60 \mathrm{~s}$ and 20s, respectively. The scattering vector q was in the range of $0.15 \sim 2.9 \mathrm{~nm}^{-1}$. To avoid overexposure, a shorter exposure time was used for longer s-d distance. All SAXS patterns were corrected for background and X-ray fluctuation. To obtain the 1D scattering profile, the relation $q=$ $4 \pi(\sin \theta) / \lambda$ was used, where $q$ is the module of scattering vector; $\theta$ is one half the scattering angle; $\lambda$ is the $\mathrm{X}$-ray wavelength.

The uniaxial tensile testing was carried out using an Instron 5564 Testing Machine at a cross head speed of $10 \mathrm{~mm} / \mathrm{min}$. The dimensions of the microinjection moulded specimens are given in Figure 1.a. The crosshead displacement was used to acquire the specimen extension. On this basis, specimen elongation at break, strain and Young's modulus were calculated. A total of ten specimens were tested for each sample at room temperature to obtain the average values for the Young's Modulus and the elongation at break. Each test was performed up to the failure point.

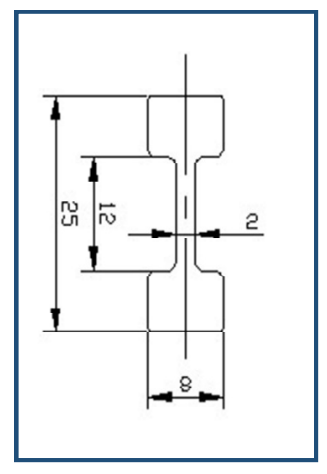

a

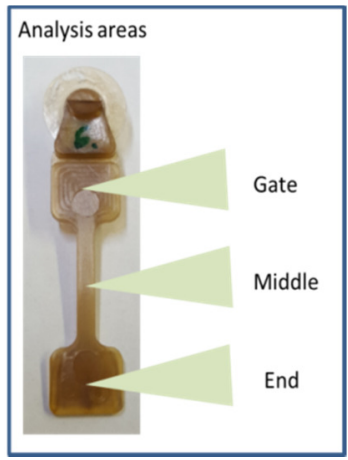

b

Fig. 1. a - Technical drawing of the microinjected moulding specimen, dimensions in $\mathrm{mm}$, thickness $1.02 \mathrm{~mm}$ process

$b$ - injected moulded part with the areas of the sample used for characterisation

\section{Results and discussion}

\section{Microinjection moulding}

Microinjection moulding of PEEK was performed on a Battenfeld Microsystem 15. This device is capable of producing products of sub-1 g mass in thermoplastics, thermosets and metal/ceramic powder materials, but the mass production of such components still faces significant challenges in terms of producing components of consistent quality due to limitations of process and product control and variations in quality of raw materials $[15,16]$.

To improve part quality, process interrogation techniques have been implemented that can provide rich data sets describing the material storage, pre-processing steps (drying, handling), plastication, injection, cooling and post process properties (shape, mechanical properties, optical properties etc) [17]. To verify the repeatability, accuracy and precision of the injection moulding process, measurements were performed on three areas of the sample using an Olympus LEXT OLS 4000, objective lens $5 x$. The three areas are on the gauge section of the test specimen, as this is the critical region where the deformation and failure occurs due to its small cross-section $[18,19]$. 
The results obtained are in line with the mould shrinkage observed for PEEK 450G (1-1.3\%) [20]. Better replication of the mould features at higher mould temperature and hold pressures is observed (Figure 2).

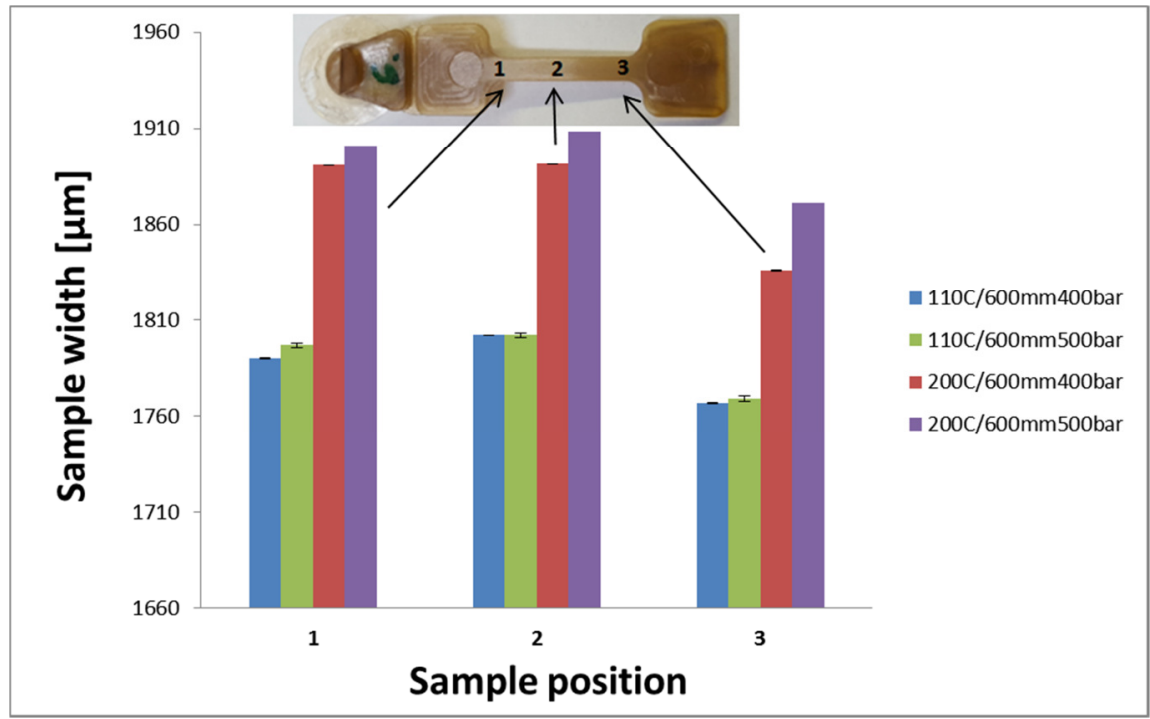

Fig. 2. Sample width variation with processing parameters

\section{XRD analysis}

In order to prove the presence of the regions with different crystallinity within one specimen, we subjected our samples to a 2D XRD analysis. Two areas were analysed for each sample as mentioned previously in Figure 1.b, i.e. middle and end positions. It is known that there are four major reflections that correspond to the orthorhombic structure of the PEEK polymers, namely (110), (111), (200) and (211) appearing at about 18.8, 20.8, 22.8 and 28.9 2theta [21]. Figure 3 shows the images and patterns for the PEEK samples processed at $600 \mathrm{~mm} / \mathrm{s}$ injection speed, 400 bar hold pressure, differing from one another by the tool temperature $\left(110^{\circ} \mathrm{C}\right.$ and $\left.200^{\circ} \mathrm{C}\right)$. It is apparent that the sample processed at $110^{\circ} \mathrm{C}$ is made mostly of an amorphous phase at the end point and is only slightly crystalline in the middle. The patterns of the samples obtained at $200^{\circ} \mathrm{C}$, on the contrary, present more intense reflections characteristic of more crystallised phase which was further used to calculate crystallinity. The presence of the diffraction peaks allowed us to calculate the crystallinity for each sample.

Crystallinity was quantified according to the formula

$$
C(\%)=\sum_{j=1}^{m} A_{j} / \sum_{i=1}^{n} A_{i} \cdot 100
$$

where the crystallinity $C$ is calculated as the ratio between the total area of $m$ crystalline peaks and the total area of all, $n$, peaks.

The results obtained for the materials produced at different injection speeds and hold pressures as well as different temperatures are given in Fig. 4, b.

Interestingly, for all analysed specimens the middle of the sample is generally more crystalline then its end point suggesting the variations of crystallinity within the specimens. It is also notable that the 
crystallinity increases with the tool temperature. The heterogeneity of PEEK crystallinity upon fast cooling from the melt for injection moulded materials has been previously hypothesised from DSC measurements [22], but it has not been confirmed by the other techniques such as XRD or FTIR.

\section{Sample processed at $600 \mathrm{~mm} / \mathrm{s}$ injection speed and hold pressure $400 \mathrm{bar}$}
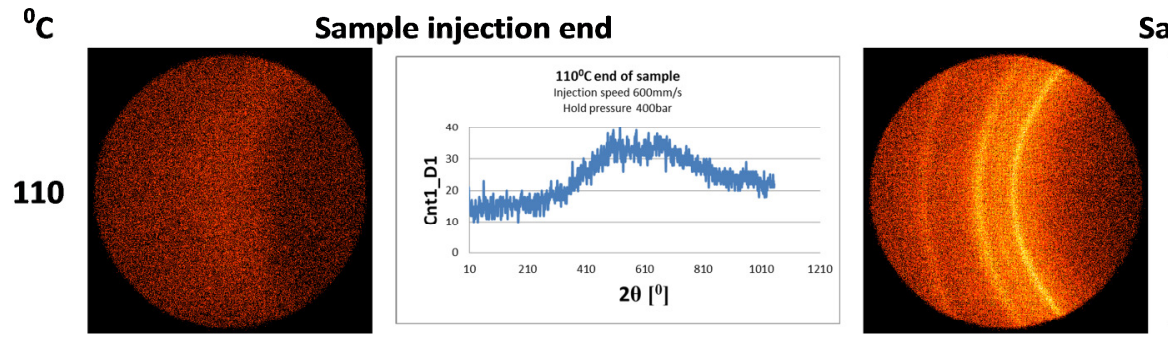

Sample centre
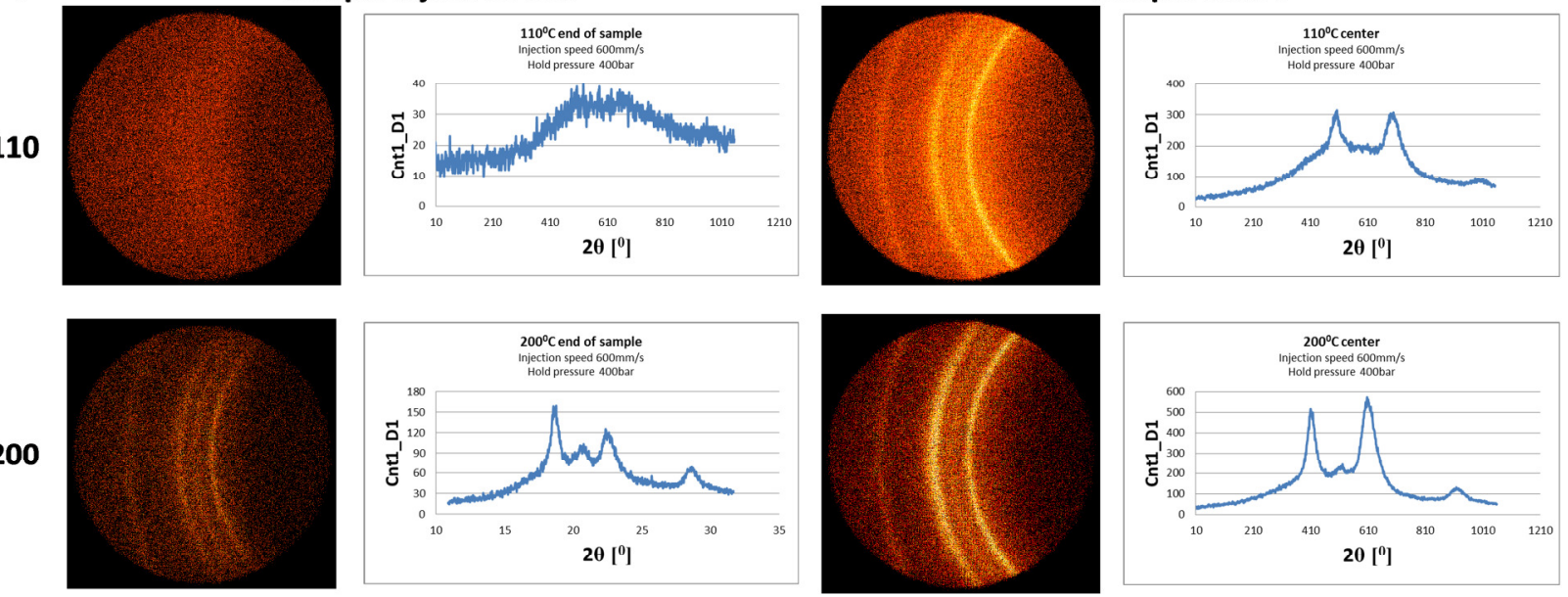

Fig. 3. Two-dimensional XRD patterns of the materials processed at $600 \mathrm{~mm} / \mathrm{s}$ injection speed and hold pressure 400 bar.
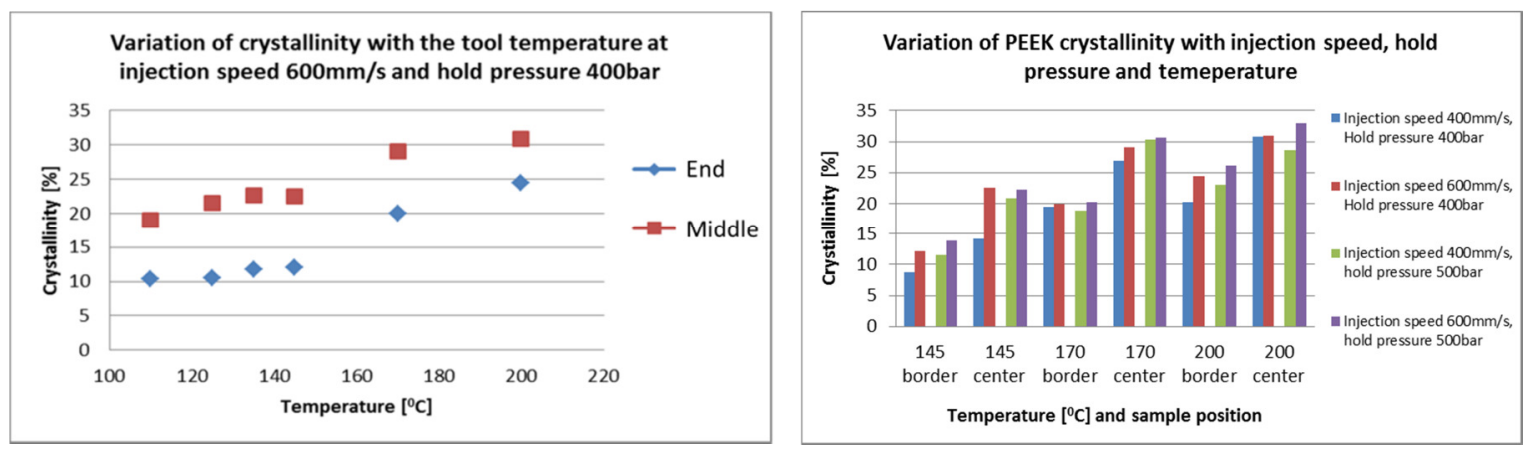

Fig. 4. Crystallinity evaluations for a - sample processed at $600 \mathrm{~mm} / \mathrm{s}$ injection speed and 400 bar hold pressure;

b - variation of PEEK crystallinity with various injection moulding parameters

As shown in Figure 4.a an inflection is observed in the vicinity of $145^{\circ} \mathrm{C}$, when the crystallinity increases by $10 \%$. Vasconcelos et al. [13] showed in their DSC cooling rates study that PEEK presents significant crystallinity independent of the temperature. It was also observed that the crystallization time for this polymer is between 5-15 minutes, meaning that, in order to promote the crystallization of this polymer, is not necessary to maintain it at high temperatures for long period of time. This is actually the scenario of microinjection moulding where the polymer forms the part and cools very quickly, but the residence time is more or less unknown.

Table 1 shows that crystallinity also increases with the injection speed and the hold pressure. A small increase at $170^{\circ} \mathrm{C}$ tool temperature at the 'end' position of the sample was observed, where the 
crystallinity seems to have reached a plateau. In the centre of the sample the crystallinity continues to increase significantly even at $170^{\circ} \mathrm{C}$. The differentiation between the border of the sample and the middle is easily observed. At $145^{\circ} \mathrm{C}$ the crystallinity in the middle of the sample is almost double then the one calculated for the border.

Table 1. Crystallinity variation with the injection moulding parameters

\begin{tabular}{|c|c|c|c|c|}
\hline \multirow{2}{*}{$\begin{array}{c}\text { Tool } \\
\text { Temperature }\left[{ }^{\circ} \mathrm{C}\right]\end{array}$} & \multirow{2}{*}{$\begin{array}{c}\text { Injection speed } \\
{[\mathrm{mm} / \mathrm{s}]}\end{array}$} & \multirow{2}{*}{$\begin{array}{l}\text { Hold pressure } \\
\text { [bar] }\end{array}$} & \multicolumn{2}{|c|}{ Crystallinity [\%] } \\
\hline & & & End & Middle \\
\hline $110^{*}$ & 600 & 400 & $10 \pm 0.8$ & $19 \pm 1.2$ \\
\hline $125^{*}$ & 600 & 400 & $11 \pm 1.5$ & $22 \pm 0.9$ \\
\hline $135^{*}$ & 600 & 400 & $12 \pm 0.9$ & $23 \pm 0.8$ \\
\hline \multirow[t]{4}{*}{145} & \multirow[t]{2}{*}{400} & 400 & $9 \pm 0.3$ & $14 \pm 0.6$ \\
\hline & & 500 & $12 \pm 1.7$ & $21 \pm 0.9$ \\
\hline & \multirow[t]{2}{*}{600} & 400 & $12 \pm 1.3$ & $23 \pm 2.1$ \\
\hline & & 500 & $14 \pm 1.3$ & $22 \pm 1.8$ \\
\hline \multirow[t]{4}{*}{170} & \multirow[t]{2}{*}{400} & 400 & $19 \pm 0.8$ & $27 \pm 1.8$ \\
\hline & & 500 & $19 \pm 0.9$ & $30 \pm 0.7$ \\
\hline & \multirow[t]{2}{*}{600} & 400 & $20 \pm 1.6$ & $29 \pm 1.6$ \\
\hline & & 500 & $20 \pm 1.2$ & $31 \pm 1.3$ \\
\hline \multirow[t]{4}{*}{200} & \multirow[t]{2}{*}{400} & 400 & $20 \pm 0.9$ & $31 \pm 2.1$ \\
\hline & & 500 & $23 \pm 1.7$ & $29 \pm 1.8$ \\
\hline & \multirow[t]{2}{*}{600} & 400 & $27 \pm 2.0$ & $31 \pm 2.2$ \\
\hline & & 500 & $26 \pm 1.9$ & $33 \pm 1.8$ \\
\hline
\end{tabular}

*experiments were performed for the full set of parameters but the cavity could not be filled for the ones not shown in the table

\section{ATR-FTIR}

FTIR spectrometer with integrated ATR attachment was used to qualitatively analyse the composition of phases in PEEK samples used for the XRD studies (Fig. 3). The typical spectra of PEEK are given in Fig. $5 a$ with the fingerprint region laying in the area between 650 and $1800 \mathrm{~cm}^{-1}$. The area in the region of 700-900 $\mathrm{cm}^{-1}$ corresponds to the ring deformation modes, whereas the bands around 1650 and $1250 \mathrm{~cm}^{-1}$ are characteristic for the carbonyl stretching. It was proposed that information on the crystallinity of the PEEK polymer can be extracted from the mid-IR spectra by evaluating the peaks that are known to vary in shape and size for the samples with different crystallinity. There are certain regions of the spectra that can be used for the crystallinity studies. Thus, it has been reported that the peaks at 1280 and $1305 \mathrm{~cm}^{-1}$ can be utilised for crystallinity evaluation [23], whereas other research groups have suggested that the peaks at 965 and $952 \mathrm{~cm}^{-1}$ can also be subjected to the phase analysis [24], with the area of interest lying within the $950 \mathrm{~cm}^{-1}$ peak where an additional shoulder of the $947 \mathrm{~cm}^{-1}$ becomes apparent when the amorphous phase is decreased [25]. In addition, a shift in carbonyl group stretching to lower wavenumbers due to the movement of the two phenyl rings can be used to indicate the crystallisation process occurrence [24]. In order to confirm the data obtained by XRD, it was decided firstly to opt for the Nguen method, that is to evaluate the ratio of the absorbances at $965 / 952 \mathrm{~cm}^{-1}$ for the samples processed 
at $600 \mathrm{~mm} / \mathrm{s}$ injection speed and 400 bar hold pressure and different temperatures $\left(110^{\circ} \mathrm{C}\right.$ and 200 ${ }^{\circ} \mathrm{C}$ ) and compare them with the data that we obtained using the XRD phase analysis. It can be seen (Fig. 5B) that the end position of the material processed at $110{ }^{\circ} \mathrm{C}$ has the lowest crystallinity (the shoulder at $965 \mathrm{~cm}^{-1}$ is the least prominent). The middle position of the sample processed at $110^{\circ} \mathrm{C}$ and the end position of the sample processed at $200{ }^{\circ} \mathrm{C}$ have approximately the same crystallinity values from XRD and the intensities of the shoulders at $965 \mathrm{~cm}^{-1}$ in FTIR are similar to one another. Finally, the highest intensity of the $965 \mathrm{~cm}^{-1}$ shoulder corresponds to the highest crystalline sample from the middle position processed at $200{ }^{\circ} \mathrm{C}$. We also deconvoluted the peaks at $950 \mathrm{~cm}^{-1}$ to qualitatively evaluate the presence of the shoulder at $947 \mathrm{~cm}^{-1}$ for more crystalline samples processed at $200{ }^{\circ} \mathrm{C}$ (Fig. $5 \mathrm{C}$ ) and also compared the peak shifts of the carbonyl stretching at 1650 $\mathrm{cm}^{-1}$ (Fig. 5D). The results obtained further support our findings from the XRD study showing the increase in crystallinity with the tool temperature and also confirmed the heterogeneity of the phases within a single specimen.
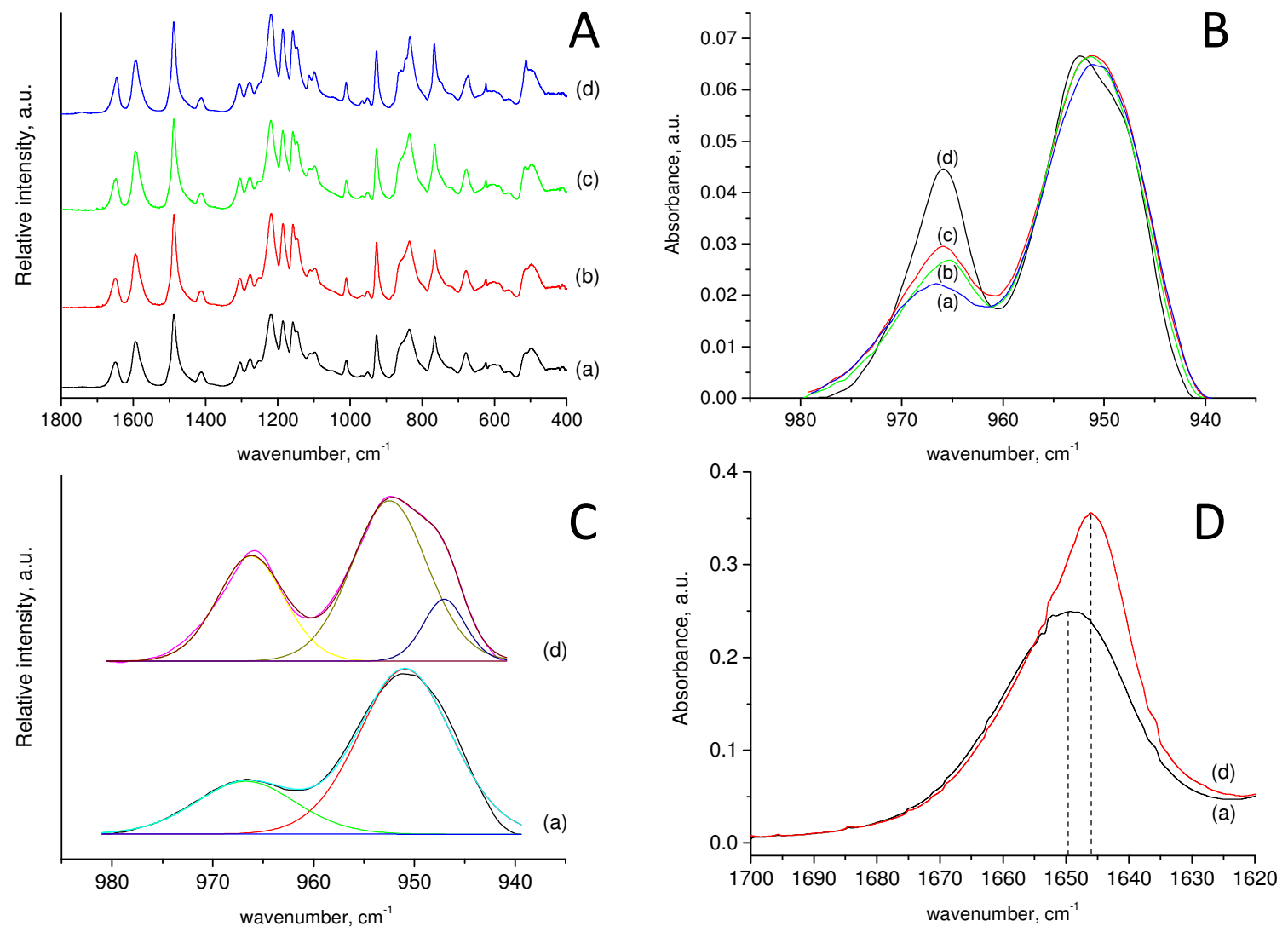

Fig. 5. FTIR spectra of PEEK materials processed at various temperatures and sample positions: (a) $110{ }^{\circ} \mathrm{C}$, end position, (b) $110{ }^{\circ} \mathrm{C}$, middle position, (c) $200^{\circ} \mathrm{C}$, end position, (d) $200^{\circ} \mathrm{C}$, and middle position. A - stack sections of spectra (a)-(d); B - fingerprint region of $980-940 \mathrm{~cm}^{-1}$ corresponding to for crystallinity variations; $C$ - fingerprint region of $980-940 \mathrm{~cm}^{-1}$, deconvoluted spectra of (a) showing two peaks and (d) with the third peak appearing; D - carbonyl group stretching region $1620-1700 \mathrm{~cm}^{-1}$ of (a) and (d), shifted to lower wavenumbers in more crystalline sample. 


\section{Light field Polarised Optical Microscopy (POM)}

Light field Polarised Optical Microscopy (POM) was used to study the microstructure of the PEEK materials. This technique employs polarised light to allow determination of the orientation, as well as crystallinity, of the polymers. Performing the observation and photography at different magnifications of the range of materials obtained at $110^{\circ} \mathrm{C}$ and $200{ }^{\circ} \mathrm{C}$ (Fig 6), it can be seen that the former represents no visible birefringence, whereas some birefringence can be detected in the latter sample. The absence of doubly-refracting areas is characteristic of poor crystallinity, whereas the interaction of the plane-polarised light with the crystalline or semi-crystalline domains results in the observation of birefringence [26].

This observation reveals the presence of amorphous and crystalline content and further complements the XRD data on the crystallinity of the PEEK specimens produced at different mould temperatures. However, this technique was not particularly efficient in visualising the spherulitic/lamellar structure that normally develops in PEEK after cooling of the melt. Also the development of spherulitic crystals is attenuated by the high shear force present in microinjection moulding, usually resulting in shish-kebab structures. This structure is typically flat lying crystallites that under polarised light will give line-like reflections instead of helical strands radiating from a nucleation point.

\section{Sample processed at $600 \mathrm{~mm} / \mathrm{s}$ injection speed and hold pressure $400 \mathrm{bar}$}

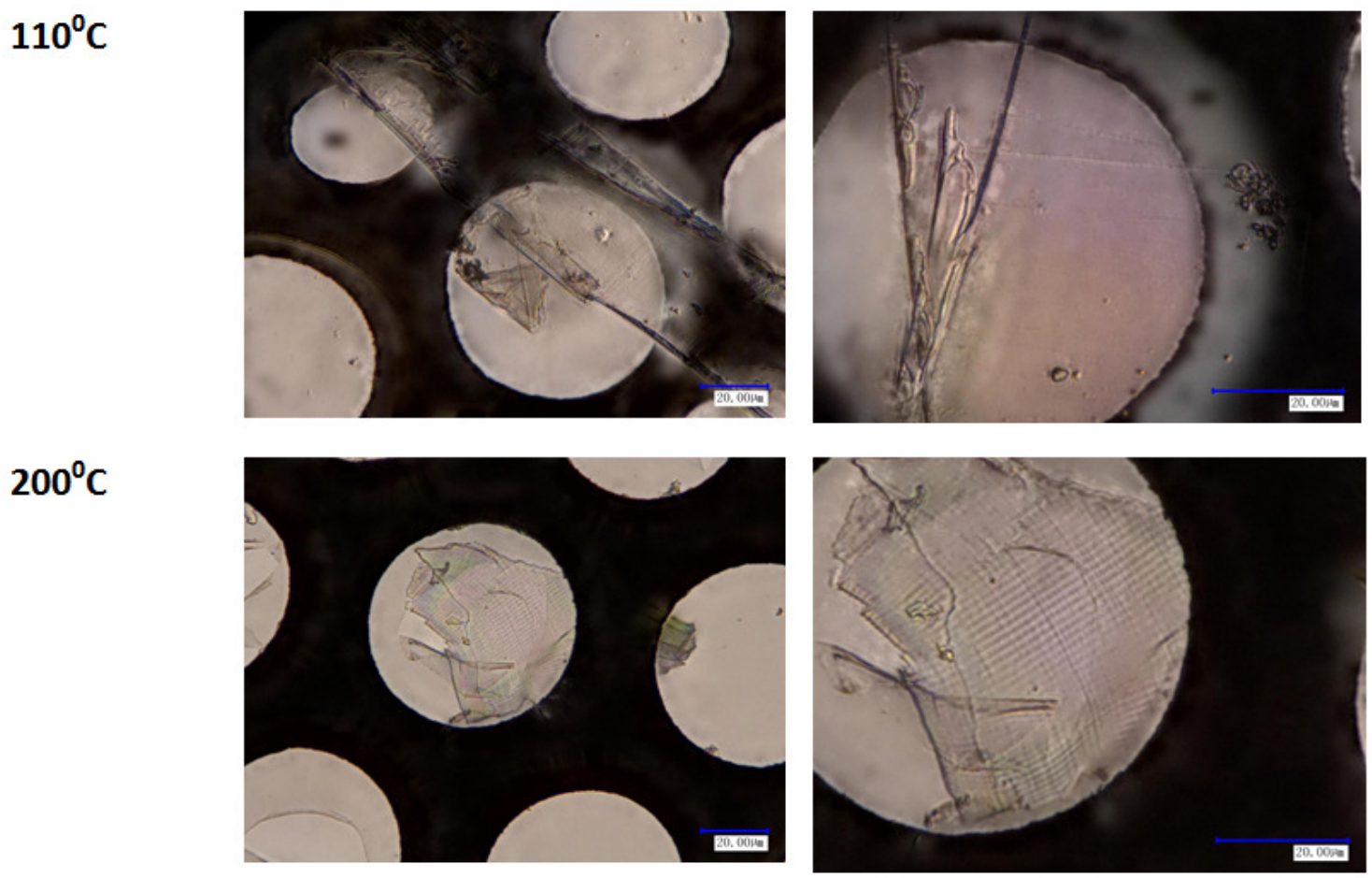

Fig. 6. Bright field polarised optical microscopy images of the cryogenic microtome cut samples produced at $600 \mathrm{~mm} / \mathrm{s}$ injection speed, 400 bar hold pressure and mould temperatures of $110^{\circ} \mathrm{C}$

(top) and $200^{\circ} \mathrm{C}$ (bottom).

Blundell et al. [27] and Ballara et al. [8] showed that the crystalline component in the case of injection moulded PEEK can vary from 0 to $40 \%$ depending on the processing history. In our case, the formation of the amorphous PEEK phase is due to the rapid cooling of the sample's outer layer, 
caused by injecting it into a mould at a temperature $300^{\circ} \mathrm{C}$ below that of the melt. Simultaneously, partially amorphous PEEK forms in the sample as the temperature of the mould increases in response to the hot injected melt. As a result of this process we are able to obtain distinct amorphous and semi-crystalline structures in one sample.

TEM

TEM was performed to further analyse the microstructure of the PEEK samples. The most representative bright field electron micrographs of the samples processed at 110 and $200{ }^{\circ} \mathrm{C}$ are shown in Fig. 7, A and B respectively. As can be seen from the micrographs, the fine structure of the materials looks predominantly homogeneous, with some parallel lines probably originating from the specimen preparation method. The resolution of the images does not discriminate between amorphous and crystalline regions, however the FFT of the specimen processed at $200{ }^{\circ} \mathrm{C}$ (see inset Fig. 7B) reveals features typically characteristic for semi-crystalline materials with predominant amorphous component. It should be noted that visualising this crystalline component would be somewhat difficult for the materials with $c a .15 \%$ crystallinity at given magnifications. Overall, this type of structure is similar with that of polyethylene terephthalate, the crystalline content of PEEK depending on its thermal processing history [27]. However, there are slight but distinct differences between the specimens prepared at different tool temperatures. The presence of dark agglomerates with average dimensions of $c a$. $20-80 \mathrm{~nm}$ can probably be attributed to the formation of spherulite regions. This corresponds to the general trend that is normally observed for the crystallisation of the PEEK polymer, i. e. the formation of spherulitic morphology upon heating above $335^{\circ} \mathrm{C}$. This trend is also observed for the amount of these regions in the samples processed at different tool temperatures - the number of dark particles is significantly higher in the samples processed at 200 ${ }^{\circ} \mathrm{C}$. Interestingly, the size of the spherulites is on average smaller than the ones previously reported [28] and no visible lamellar structure can be observed at 20K magnification (approx. $100 \mathrm{~nm}$ scale bar). This may be attributed to the fact that PEEK crystals consist of very fine lamellae that under certain conditions can organize into larger spherulites as mentioned by Kumar et al. The processing conditions play a crucial role in the thickness of these lamellae, and the size and density of spherulites [27]. Blundell and Osborn [27] measured the size of the PEEK lamellar thickness in the range 0.005 to $0.006 \mu$ mand one of the spherulites as 25 to $40 \mu \mathrm{m}$ in diameter [27]. The size of the observed structures in our TEM images is smaller than the spherulites size mentioned by Blundell, but Cebe and Hong [29] showed that different processing conditions could lead to the identification of individual spherulites or the structure can appear as a "fine grained mosaic structure", which is our case. 

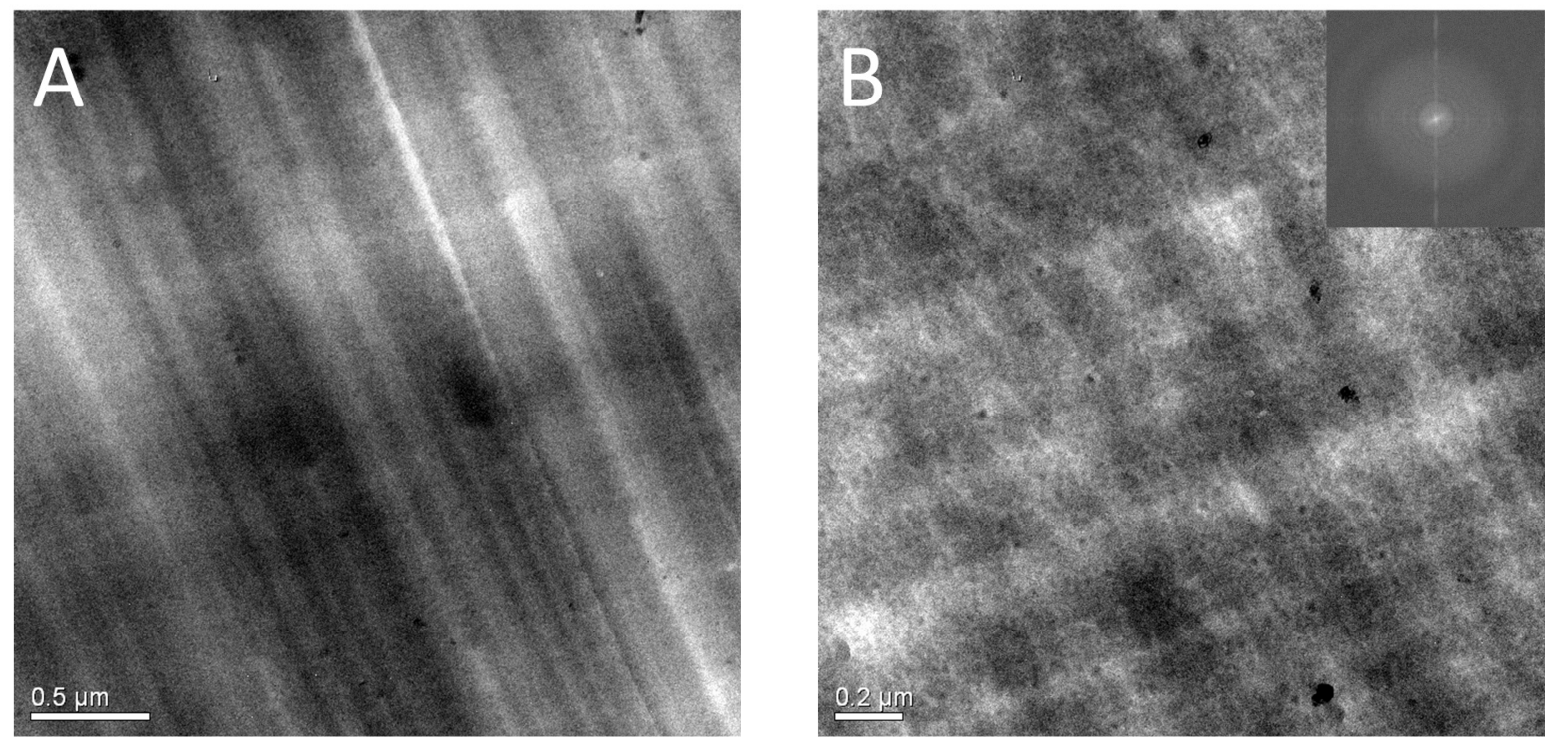

Fig. 7. Bright field TEM micrographs of PEEK material A - processed at $110^{\circ} \mathrm{C}$ tool temperature and $\mathrm{B}$ $-200^{\circ} \mathrm{C}$ tool temperature, $(600 \mathrm{~mm} / \mathrm{s}$ injection speed, 400 bar hold pressure), inset on Fig. $7 \mathrm{~b}$ is an FFT of the image.

In the case of microinjection moulding the temperature can also vary across the mould due to its surface finish (thermal contact resistance), and the shear force is different at different locations. This results in heterogeneous crystallinity, which is very common in microinjection moulding: a "skin" layer with lower crystallinity and the bulk core more fully crystallised [8, 30].

\section{SAXS}

SAXS patterns were collected at the centre and end position of samples. To analyse the data we used the Kratky method [14].

A Kratky plot shows the deviation from the high-q behaviour of the scattering intensity I(q). For polymer chains, the Kratky plot ( $q^{2} I(q)$ vs $q$ ) emphasizes the Gaussian chain nature or the branching from it. Since the form factor for Gaussian chains varies like $I(q) \sim 1 / q^{2}$ at high-q, this plot tends to a horizontal asymptote. Deviations from the horizontal asymptotic behaviour indicate a non-Gaussian characteristic for the scattering chains. For example, for rigid rods this plot would go to a linearly increasing asymptote $\mathrm{q}^{2} \mathrm{I}=\mathrm{A}+\mathrm{Bq}$ because the form factor for a rod varies like $\mathrm{I}(\mathrm{q}) \sim 1 / \mathrm{q}$. At high $\mathrm{q}$, to recover the horizontal asymptote must be use a more suitable approximation like the Kratky plot for a rod (ql vs q).

Three functions that die out differently at high q are considered:

(1) for rigid rods where $\mathrm{I}(\mathrm{x})=\mathrm{I}_{0} /(1+\mathrm{x})$

(2) for Gaussian chains where $I(x)=I_{0} /\left(1+x^{2}\right)$

(3) for branched systems (or mass fractals) where $\mathrm{I}(\mathrm{x})=\mathrm{I}_{0} /\left(1+\mathrm{x}^{3}\right)$.

Where: $\mathrm{x}$ is the dimensionless variable $\mathrm{x}=\mathrm{q} \xi$, 
$\xi$ is a characteristic length (radius of gyration or correlation length). These functions reproduce the proper low $\mathrm{x}$ and high $\mathrm{x}$ limits.

Gaussian chains tend to the Kratky plot limit of 1 . Stiff chains (for example rigid rods) increase linearly at high $x$ and branched systems (mass fractals) reach a maximum then decrease as $1 / x$ at high $\mathrm{x}$.

From the SAXS (Figure 8) data we observed that at the 'end' sample position the crystallinity increased with increase in mould temperature, the long periods decreased with increase in mould temperature, and the lamella thicknesses are very similar at the various mould temperatures.

Also, at the 'end' position (Figure 8. c) if we compare the data according with the injection speed the long periods and the lamella thickness are not changing. The crystallinity is inversely proportional to the injection speed (Figure 8. b).

The hold pressures, at the 'end' position, do not influence the long periods, the lamella thicknesses or the crystallinity.

End

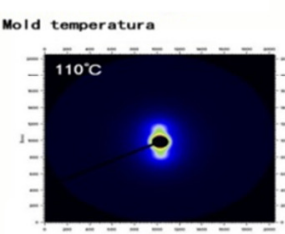

Middle
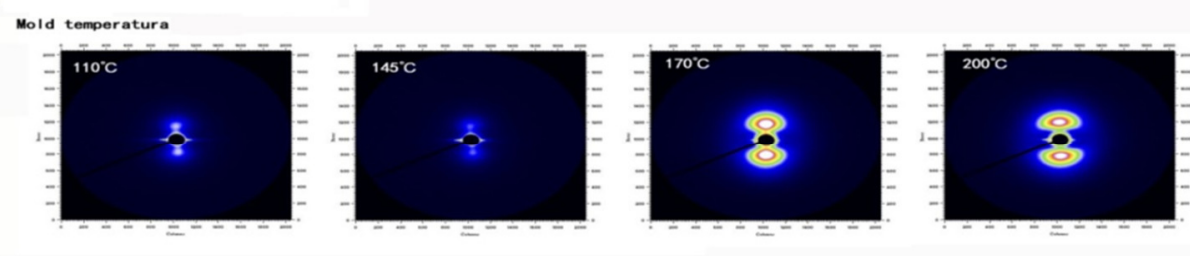

a
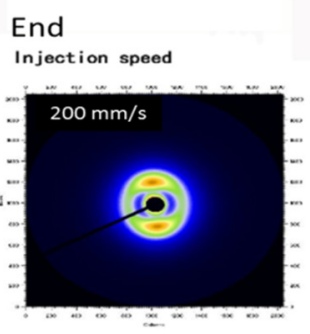

Middle

Injection speed

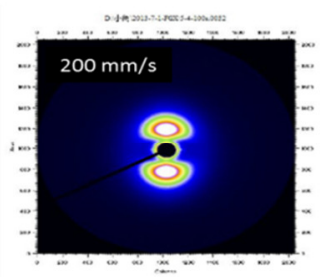

Injection speed $600 \mathrm{~mm} / \mathrm{s}$

Hold pressure 400 bar
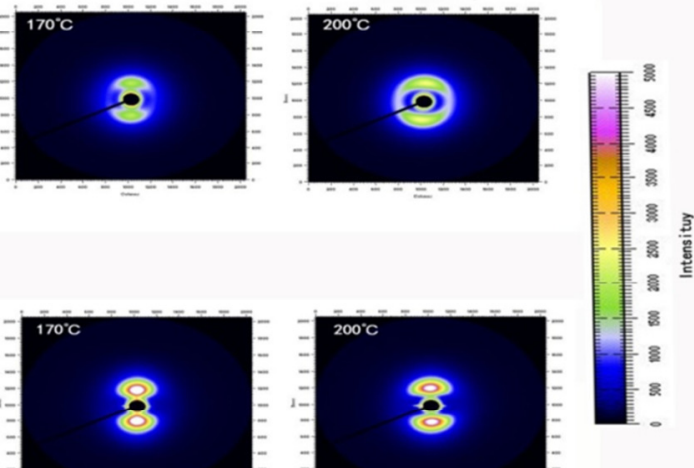

Mould temperature $200^{\circ} \mathrm{C}$

Hold pressure 500 bar
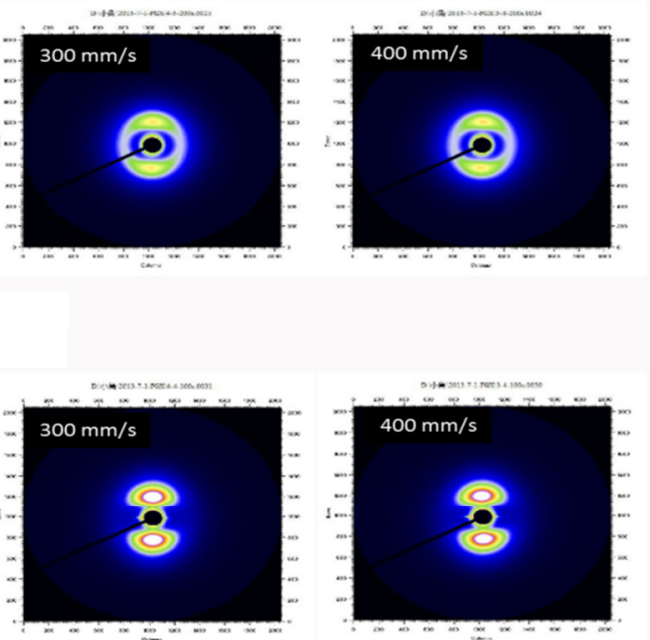

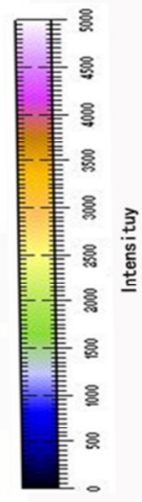

b 


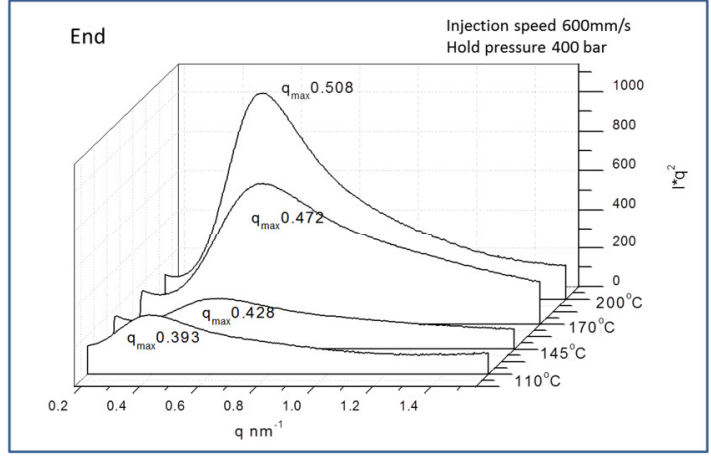

C

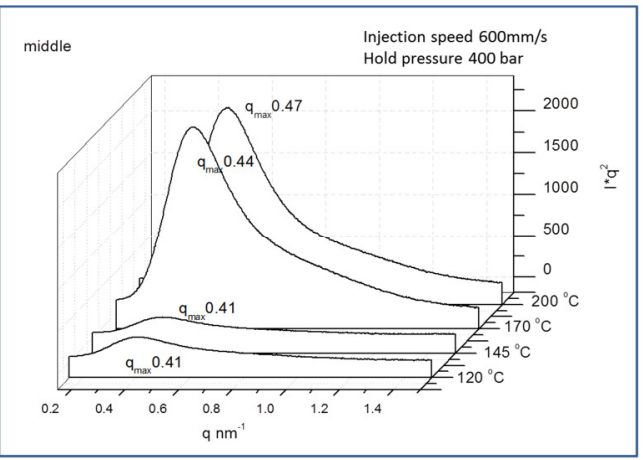

d

Fig 8. Example of SAXS analysis for samples processed at $600 \mathrm{~mm} / \mathrm{s}$ injection speed and $400 \mathrm{bar}$ hold pressure.

a - SAXS pattern collected showing spread lamellae reflection at different mould temperature for $600 \mathrm{~mm} / \mathrm{s}$ injection speed and 400 bar hold pressure

b - SAXS pattern collected showing spread lamellae reflection for different injection speeds at $200^{\circ} \mathrm{C}$ mould temperature and 500 bar hold pressure

b, $c$-The Kratky Plot for various mould temperatures at the end and in the middle of the sample respectively.

In the middle of the samples (Figure 8.d) at different mould temperatures the long periods are not changing as well as lamella thickness. The crystallinity is increasing with the decrease of the injection speed.

In the middle the hold pressure doesn't have major influence on all the three analysed parameters.

Concluding on the SAXS results, the following correlations between the injection moulding parameters and the morphology of the samples were observed:

a - mould temperature: the crystallinity increased with increase in mould temperature, the long periods decreased with increase in mould temperature, the lamella thicknesses were similar for different mould temperatures, but long period decreased, confirming that the crystallinity increased.

b - injection speed: the crystallinity increased with decrease in injection speed, because the sample thickness is the same, long periods and the lamella thickness are constant, , and the intensity increasing with decrease in injection speed.

c- hold pressure: the long periods, the lamella thicknesses and the crystallinity are not influenced.

$d$ - location: at the 'end' position the lamella thicknesses are shorter than in the 'middle' of the sample, and the crystallinity is lower. The long periods are not influenced by the locations.

\section{Tensile testing}

PEEK is a well know polymer for high strength and stiffness as well as high ductility. As a semicrystalline polymer, PEEK has a spherulitic structure [26] and deforms through the elongation of the amorphous tie chains and the tilting of the lamellar chain. The lamellar chains folds towards the 
tensile direction and the crystalline block segments separate resulting in the orientation of the segments and tie chains in the tensile direction.

At a macroscopic level PEEK deformation involves upper and lower yield point and necking. In the case of PEEK, and polymers generally, the neck gets stronger [31,32] since the deformation aligns the chains. The tensile modulus usually decreases with increasing temperature and diminishing strain rate.

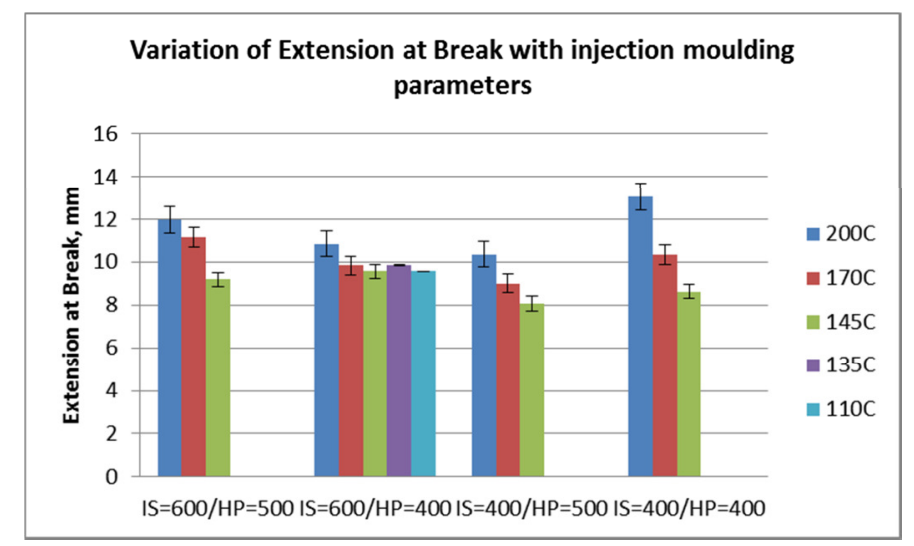

Fig. 9. Variation of Extension at Break with mould temperature, injection speed and hold pressure

The stress-strain curve of the sample processed between $170^{\circ} \mathrm{C}$ and $200^{\circ} \mathrm{C}$, as advised in the data sheet, exhibits ductile behaviour. The elongation at the break (Figure 9) decreases with the tool temperature. It was expected that the elongation at break would increase with the decrease of the tool temperature as the amorphous phase is more ductile.

On the other hand, the Young's Modulus of samples (Figure 10) increases with the mould temperature. No significant variation is observed with the injection speed and hold pressure. This behaviour was expected as amorphous PEEK phases are expected to be mechanically weaker than the semi crystalline one. The crystallization rates are dictated by the type of S-curves [33] and therefore nucleation becomes slower at higher temperatures. Our tests confirm that higher crystallinity increases strength, as the secondary bonding is enhanced, this being translated in closely packed and parallel molecular chains. The tensile test is resembles a pre-deformation by drawing, leading to increased strength by orienting the molecular chains.
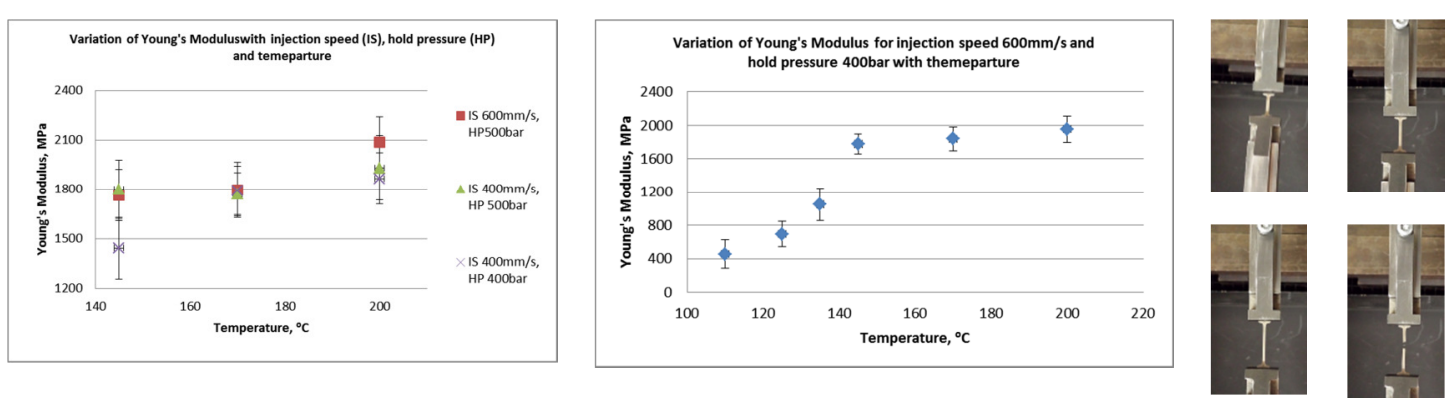

Fig. 10. Young's modulus variation with tool temperature, injection speed and hold pressure

Mijovic and Gsell [34] evaluated, using DSC, the relationship between mechanical properties and crystallinity of implant components fabricated from PEEK, and showed the connection between these properties and the manufacturing process. 


\section{Discussion}

Cebe [29] and Jenkins [35] described crystallinity (C) over time ( $t$ ) in PEEK using the Avrami relationship in isothermal conditions:

$$
C(t)=1-\exp \left(k t^{n}\right)
$$

where:

$-k$ is the growth of nucleation in the polymer

- $\mathrm{n}$ depends on the mechanism of nucleation

For PEEK $n=3$, and the $k$ value ranges over three orders of magnitude depending upon the temperature chosen for the isothermal crystallization experiment [29]. In order to characterise PEEK under non-isothermal conditions, methods of characterisation such as XRD, FTIR, SEM, SAXS, etc are employed to determine crystallinity. This kind of tactic was employed also in this paper to fully characterise the microinjected samples.

In our case the mechanical test results indicate that our PEEK samples might contain rigid fully crystalline areas dispersed in amorphous regions [36]. This behaviour changes across the sample: the border of the sample is hosting an amorphous phase with islands of crystalline material, wheras the centre of the sample is a largely crystallised material with amorphous inclusions. Hay et al. [21] mentioned that the variability of the density with crystallization temperature can be linked to the presence of crystalline regions within the amorphous regions.

As a basis for comparison, spinal vertebra cancellous bone has Young's Modulus values ranging from $87(100)$ to $791(700) \mathrm{MPa}[37,38]$. There are a number of sources of mechanical data on PEEK and related composites. Toth et al. [12] studied the PEEK-Optima (Invibio, Greenville, SC) and they obtained the following mechanical properties: Young's modulus of $3.7 \mathrm{GPa}$, tensile strength of 100 $\mathrm{MPa}$, and ductility of $60 \%$ elongation to failure. Kurtz and Devine [1] reported the achievement of reduction of the UTS by $45 \%$, to $44 \mathrm{MPa}$ by loading PEEK with $40 \% \mathrm{HA}$, which is comparable to cortical bone. This shows that it is an interest for the implants to simulate as close as possible the morphology of the bone structure encountered in the body.

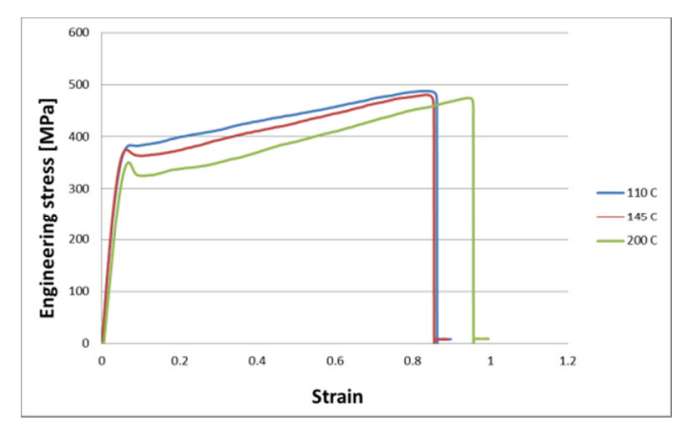

Figure 11. Representative engineering stress-strain curves for samples processed at injection speed $600 \mathrm{~mm} / \mathrm{s}$ and hold pressure $400 \mathrm{bar}$ at three mould temperatures.

Typical results of our tensile tests are shown in Figure 11. One can observe that the samples behave quite similarly in the elastic region. The yield point, and the material behaviour, changes significantly with the tool temperature and subsequently the crystallinity. The plastic region is very similar for the samples produced at $110^{\circ} \mathrm{C}$ and $145^{\circ} \mathrm{C}$ and is expanded for the $200^{\circ} \mathrm{C}$ samples. 
The mechanical properties of our various samples show a variation of the Young's modulus from $400 \mathrm{MPa}$ at mould temperature $110^{\circ} \mathrm{C}$ to $2000 \mathrm{MPa}$ at mould temperature $200^{\circ} \mathrm{C}$. Figure 8.c shows the variation of Young's Modulus at different tool temperature and we can observe that we can obtain at temperatures between $110^{\circ} \mathrm{C}$ and $130^{\circ} \mathrm{C}$ PEEK samples with mechanical properties very close to those of the human cortical bone (100-700MPa). To date PEEK spinal implants are produced at high tool temperature which result in Young's Moduli of 3700MPa [12], values very dissimilar to the one of the physiological body part that they replace.

These implants bear a load or stress and will eventually cause failure unless the body fuses or heals at the site. Failure as: increasing disc height loss, degeneration, disc bulge and/or protrusions as well as progressive facet arthropathie are common and predictive [39]. Adjacent vertebral body fractures and collapse have been reported especially in osteoporotic cases [40].

Kurtz [41] mentioned that PEEK biomaterials have more than a decade of successful clinical history in spinal fusion applications. PEEK polymers continue to influence the direction of spinal device design. He stressed that with or without motion preservation, the need for advancement in biomaterials is anticipated to continue in spinal surgery. This is due to patient requirements for faster, less invasive treatments to achieve spinal fusion. Preserving motion and spinal stability in various patient populations is the main focus. He argued that much like the field of instrumented spine surgery, PEEK must continue to evolve.

The growing interest in enhancing the osseoconductivity of PEEK to provide direct bone on-growth and to follow the advances made in porous metals technology to allow bone in-growth in 3-D interconnected porous PEEK structures are just few of the main factors that triggered our further investigation $[1,42]$.

When bone grafts and metal pins, used to fill the resulting space during surgery and to help support the spine while it heals back together, were replaced by PEEK that is mechanically strong and harder wearing, a new door in spinal surgery was opened. By creating a PEEK device that is biologically active, for example able to stimulate new bone growth is the way to go forward and to build a successful platform. Such a material would eliminate the need for grafts, reduce the number of operations necessary and lead to faster bone fusion and better treatment.

\section{Conclusions}

In the present study we report on the evaluation of the correlation between the processing history and the mechanical and physico-chemical properties of microinjection moulded PEEK material. We have shown that microinjection moulding can be successfully used for the processing of PEEK material with high precision and accuracy. It was also demonstrated that the variation in processing parameters, such as tool temperature, injection speeds and hold pressures allows controllable manipulation of the morphology of the PEEK. We also showed that micro injection moulding allows the production of materials with spatially heterogeneous crystallinity which could be of a significant importance for producing materials emulating the bone and the cartilage together. The morphology of these materials has been studied using a variety of spectroscopic (ATR-FTIR), X-Ray (SAXS, 2dimentional XRD) and microscopy tools (polarised optical microscopy, TEM), and the results obtained complement each other verifying the variations in crystallinity not only between the samples but also within one sample. Tensile testing results have revealed that components obtained at different tool temperatures present variations in mechanical properties similar to those in spinal cancellous bone. Thus, we have shown that microinjection moulding enables production of PEEK 
materials with controllable crystallinity that has a potential to be used as biomaterials in spinal and other orthopaedic applications.

Acknowledgments: Science Bridges: Bradford-China Programme for Pharmaceutical Sciences and Medical Technology, EP/G042365/1

\section{References}

[1] Kurtz, S.M., Devine, J.N., PEEK biomaterials in trauma, orthopedic, and spinal implants, Biomaterials 28 (2007) 4845-4869

[2] May R., Polyetheretherketones, Encyclopedia of polymer science and engineering, New York: Wiley; 1988. p. 313-20.

[3] Rigby R.B., Polyetheretherketone, Engineering thermoplastics: properties and applications, New York: Marcel Dekker, Inc.; 1985. p. 299-314.

[4] Sasuga T., Hagiwara M., Radiation deterioration of several aromatic polymers under oxidative conditions, Polymer 1987;28(11):1915-21.

[5] Folkes, M.J., Kalay, G., Ankara, A., The effect of heat treatment on the properties of peek and APC2, Composites Science and Technology, Volume 46, Issue 1, 1993, Pages 77-83.

[6] Chena, F., Oua, H., Lub,B., Long, H., A constitutive model of polyether-ether-ketone (PEEK), Journal of the Mechanical Behavior of Biomedical Materials, Volume 53, January 2016, Pages 427-433.

[7] Blundell, D.J., Osborn, B.N., The morphology of poly(aryl-etherketone), Polymer 1983;24:953.

[8] Ballara, A., Trotignon, J.P., Verdu, J., Skin-core structure of polyetheretherketone injection moulded parts from DSC measurements, J Mater Sci Lett 1986;5:706-8.

[9] Nguyen,H.X., Ishida, H., Poly(aryl-ether-ether-ketone) and its advanced composites: A review, Polymer composites, Volume 8, Issue 2, April 1987, Pages 57-73.

[10] Jones, D.P., Leach, D.C., Moore, D.R., Mechanical properties of poly(ether-ether-ketone) for engineering applications, Polymer 1985; 26:1385-93.

[11] (HLG) H.L.E.G (2011) Key enabling technologies-final report, European Commission, Retrieved from http://ec.europa.eu/enterprise/sectors/ict/files/kets/hlg report final en.pdf

[12] Toth, J.M., Wanga, M., Estes, B.T., Scifertd,J.L., Seim III, H.B., Turner, A.S., Polyetheretherketone as a biomaterial for spinal applications, Biomaterials 27 (2006) 324-334.

[13] Da Cunha Vasconcelos, G., Lago Mazur, R., Cocchieri Botelho, E., Cerqueira Rezende, M., Leali Costa, M., Evaluation of crystallization kinetics of poly (ether-ketone-ketone) and poly (etherether-ketone) by DSC, J. Aerosp.Technol. Manag., São José dos Campos, Vol.2, No.2, pp. 155162, May-Aug., 2010.

[14] Verma, R.K, Velikov, V., Kandert, R.G., Marand, H., Chu, B., Hsiao, B.S., SAXS studies of lamellar level morphological changes during crystallization and melting in PEEK, Polymer Vol. 37 No. 24, pp. 5357-5365, 1996.

[15] Vella P.C., Dimov S.S., Brousseau E, Tuinea-Bobe C., Grant C. and Whiteside B.R., "A new process chain for producing bulk metallic glass replication masters with micro- and nano-scale features", The International Journal of Advanced Manufacturing Technology, 2014.

[16] Gao, Y., , X., Wang, L., Liu, G., Liu, X., Tuinea-Bobe, C.L., Whiteside, B., Coates, P., Wang, D., Han, C.C., Flow-induced crystallization of long chain aliphatic polyamides under a complex flow field: Inverted anisotropic structure and formation mechanism, Polymer Volume 73, 2 September 2015, Pages 91-101. 
[17] Wöhner, T., Whiteside, B.R., Tosello, G., Hans Nørgaard, H., Aminul, I., Influence of Process Temperatures on Blister Creation in Micro Film Insert Molding of a Dual Layer Membrane, Proceedings of the 11th International Conference on Multi-Material Micro Manufacture (4M2016) : co-organised with 10th International Workshop on Microfactories (IWMF2016).

[18] Czichos,H., Saito,T., Smith, L.E., Springer Handbook of Materials Measurement Methods. Berlin: Springer, pp. 303-304, ISBN 978-3-540-20785-6, 2006.

[19] Davis, J.R., Tensile testing (2nd ed.), ASM International, ISBN 978-0-87170-806-9, 2004.

[20] VICTREX PEEK 450G data sheet (3/10/2017, 16:10), www.victrex.com/ $/$ media/datasheets/victrex tds 450g.pdf

[21] Hay, J.M., Langford, J.I., Lloyd, J.R., Variation in unit cell parameters of aromatic polymers with crystallization temperature, Polymer 1989; 30:489-93.

[22] Lovinger, A.J., Davis, D. D., Solution Crystallization of Poly(ether ether ketone), Macromolecules,19, 1861-1867, 1986

[23] Chalmers, J.M., W.F. Gaskin, M.W. Mackenzie, Crystallinity in Poly(aryl-ether-ketone) Plaques Studied by Multiple Internal-reflection Spectroscopy, Polymer Bulletin, 1984. 11(5): p. 433-435.

[24] Nguyen, H.X., Ishida, H., Molecular analysis of the melting behaviour of poly(aryl-ether-etherketone), Polymer, 1986, 27(9): p. 1400-1405.

[25] Jonas, A., R. Legras, and J.P. Issi, Differential Scanning Calorimetry and Infrared Crystallinity Determinations of Poly(aryl ether ether ketone), Polymer, 1991, 32(18): p. 3364-3370.

[26] Kurtz, S.M., PEEK Biomaterials Handbook, Elsevier, 2012, p. 87-90.

[27] Blundell D.J., Osborn B.N., The morphology of poly(aryl-etherketone, Polymer 1983;24:953

[28] Kumar S, Anderson DP, Crystallization and morphology of poly(aryl-ether-etherketone, Polymer 1986;27:329.

[29] Cebe P., Hong, S.D., Crystallization behaviour of polyetheretherketone, Polymer 1986;27(8):1183-92.

[30] Hobbs, S. Y., Pratt, C. F., The effect of skin-core morphology on the impact fracture of poly(butyline terephthalate), Applied Polymer Science, Volume 19, Issue 6 June 1975, p. 1701-1722.

[31] Ward, I. M., Coates, P.D., Solid Phase Processing of Polymers, Hanser, 2000.

[32] Ward, I. M., Mechanical properties of oriented polymers, POLYMER, 15, 379-386, 1974.

[33] Mandelkern, L., Crystallization of Polymers, McGraw-Hill, New York, 1964.

[34] Mijovic J, Gsell TC, Calorimetric study of polyetheretherketone (PEEK) and its carbon fiber composite, SAMPE Q 1990;21(2):42-6.

[35] Jenkins, M.J., Hay, J.N., Terrill, N.J., Structure evolution in melt crystallized PEEK, Polymer 2003;44:6781-7.

[36] Cheng, S.Z.D., Cao, M.Y., Wunderlich B., Glass transition and melting behavior of poly(oxy-1,4phenyleneoxy-1,4-phenylenecarbonyl-1,4-phenylene, Macromolecules 1986;19:1868-76.

[37] El Masri, F., Sapin de Brosses, E., Rhissassi, K., Skalli, W., Mitton, D., Apparent Young's modulus of vertebral cortico-cancellous bone specimens, Comput Methods Biomech Biomed Engin. 2012;15(1):23-8. doi: 10.1080/10255842.2011.565751, Epub 2011 Jul 13

[38] Banse, X., Sims, T.J., Bailey, A.J., Mechanical Properties of Adult Vertebral Cancellous Bone: Correlation With Collagen Intermolecular Cross-Links, Journal of bone and mineral research, Volume 17, Number 9, 2002.

[39] Liao, J.C., Niu, C.C, Chen, W.J., Chen, L.H., Polyetheretherketone (PEEK) cage filled with cancellous allograft in anterior cervical discectomy and fusion, Int Orthop. 2008 Oct; 32(5): 643648.

[40] Kim, M.H., Lee, A.S., Min, S.H., Yoon, S.H., Risk Factors of New Compression Fractures in Adjacent Vertebrae after Percutaneous Vertebroplasty, Asian Spine Journal, 2011 Sep; 5(3): 180-187. 
[41] M. Kurtz, S.M., Implantable PEEK Polymers: A Decade of Progress in Spine, https://www.odtmag.com/contents/view features/2010-02-11/implantable-peek-polymers--adecade-of-progre/ (6/10/2017, 11:48).

[42] Vaezi, M., Yang, S., A novel bioactive PEEK/HA composite with controlled 3D interconnected HA network, International journal of Bioprinting, Vol 1, No 1 (2015). 